\title{
CENAS DA ESCRITA DISTOPICA EM GOLGONA ANGHEL
}

\section{SCENES OF DYSTOPIAN WRITINGS IN GOLGONA ANGHEL}

\author{
http://dx.doi.org/10.11606/issn.2175-3180.v13i25p97-111
}

Paulo Alberto da Silva Sales I

\section{RESUMO}

Reflexão sobre a poesia de Golgona Anghel discutindo a relação entre poesia e ética na contemporaneidade. Constata-se, por meio de uma escrita atenta ao cotidiano da cidade (Lisboa) e às vivências do tempo presente, uma discursividade construída por meio da "partilha do sensível", ou seja, por uma linguagem que afeta os sujeitos e que os leva à consciência da realidade marcada por fracassos e perdas. Observa-se nos gestos de escrita, principalmente nas obras Como uma flor de plástico na montra de um talho (2013) e Nadar na piscina dos pequenos (2017), uma dicção irônica e risível que revela um modo de narrar/partilhar o real em uma poética afetuosa na qual poeta e sujeitos compartilham do desencanto da sociedade do espetáculo. Conclui-se que a distopia latente nas cenas de escrita dos poemas é equilibrada pela partilha de uma linguagem que vai ao encontro do outro.

\section{PALAVRAS-CHAVE}

Poesia portuguesa contemporânea; Golgona Anghel; Ética; Ironia.

\section{ABSTRACT}

Reflection on Golgona Anghel's poetry by the analysis of relationship between poetry and ethic in contemporary times. Note by the writing attentive to the daily city (Lisbon) and the present time experiences that there is a discursiveness built by the "sharing the sensitive". In other words, it is a language that affects the subjects and it brings them into the reality consciousness marked by failures and loss. It is observed in the writing gestures mainly in the works Como uma flor de plástico na montra de um talho (2013) and Nadar na piscina dos pequenos (2017) an ironic and laugh diction that reveals narration/sharing mode of the real in an affective poetic in which the poet and the subjects sharing the show society disenchantment. Concludes that the latent dystopia in the poems writing scenes is balanced by sharing of a language that goes against the other.

\section{KEYWORDS}

Portuguese contemporary poetry; Golgona Anghel; Ethic; Irony.

\footnotetext{
I Instituto Federal Goiano, Hidrolândia, Goiás, Brasil; Universidade Estadual de Goiás, Goiás, Goiás, Brasil.
} 
"há um poeta da entrega e da partilha de sentimentos, e há um poeta da recusa e da negatividade; há um poeta da condensação narrativa que vale como aglutinação imagética, e há um poeta das longas tiranias do desencanto e da morte; [...] e [há] o poeta das fantasmagorias sinistras do tempo que lhe coube viver e da prosa banal do quotidiano que absorve completamente a vida". António Guerreiro. Um pouco de vida, um pouco de poesia.

Por meio da leitura do ensaio "Um pouco de vida, um pouco de poesia", do crítico português António Guerreiro (2003), publicado na revista Telhados de vidro, destacamos a ideia de que há poetas, na recente poesia portuguesa, da entrega, da negatividade, da recusa e da apropriação da prosa banal do cotidiano para a construção de cenas de uma escrita distópica sobre a cidade de Lisboa. Muito embora Guerreiro se refira à produção poética de Joaquim Manuel Magalhães ${ }^{1}$, importante voz da poesia portuguesa surgida na década de 1970, tais linhas de força se encontram em estado de latência na poesia de Golgona Anghel (1979 - ), autora de livros publicados a partir dos anos 2000, tanto de crítica sobre a obra de $\mathrm{Al} \mathrm{Berto}{ }^{2}$ quanto de outros poetas, sendo a sua lírica nosso foco de reflexão. Interessa-nos destacar, por meio da leitura de poemas pertencentes às obras Como uma flor de plástico na montra de um talho (2013) e Nadar na piscina dos pequenos (2017), os modos pelos quais a escrita dessa poeta problematiza aspectos do espaço urbano contemporâneo e o encontro com sujeitos anônimos, todos marcados por sentimento de perda e de vazio cotidianos. A poeta e os habitantes da cidade partilham, então, uma mesma sintaxe discursiva, oralizada e repleta de referências a objetos e a lugares comuns da ordem cultural do capitalismo tardio. Nos poemas, há cenas atravessadas por uma fraternidade em que se constrói um lugar comum de partilha de problemas entre os sujeitos deslocados. Esses momentos de partilha entre a poeta e os sujeitos citadinos são circunscritos em micropaisagens que os possibilitam estar em conjunto, identificando uns com os problemas dos outros, tal como se lê no poema "Pouco importa que entrem pela casa adentro":

Pouco importa que entrem pela casa dentro

malucos e ladrões,

moscas ou carros blindados,

\footnotetext{
${ }^{1}$ Doravante, sempre que nos referirmos ao poeta, usaremos JMM.

2 Destacamos as obras Eis-me acordado muito tempo depois de mim: uma biografia de Al Berto (2006) e Diários (2012), da editora Assírio \& Alvim.
} 


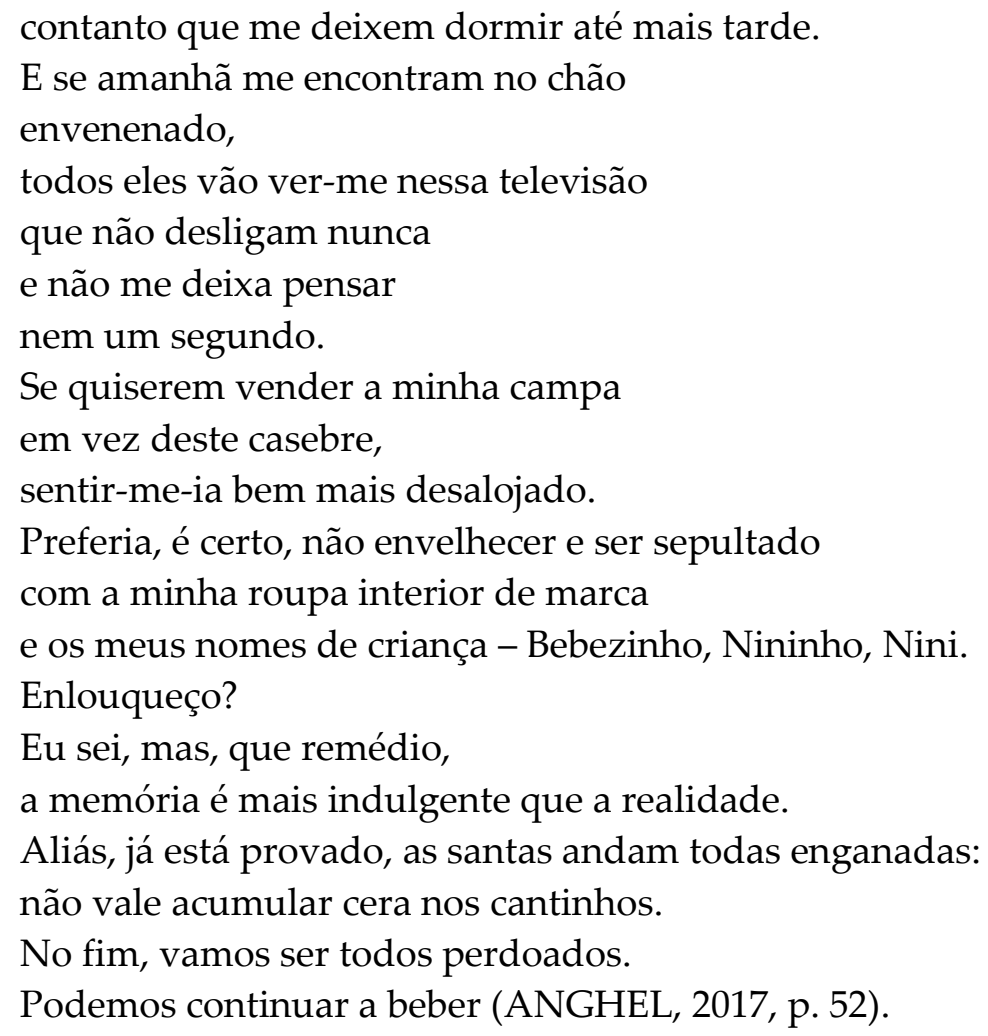

Nota-se que a poeta se identifica com diversas patologias do mundo moderno e contemporâneo (ansiedade, depressão, etilismo, suicídio, etc.) que acometem os anônimos "malucos" de Lisboa: "E se amanhã me encontram no chão / envenenado, / todos eles vão ver-me nessa televisão / que não desliga nunca / e não me deixa pensar / nem um segundo". Como uma espécie de flâneur, que caminha pelas ruas da cidade, ela se reconhece como um sujeito comum que enfrenta os mesmos infortúnios que acometem os transeuntes que cruzam pelas avenidas, ruas, becos, calçadas, comércios, casas. Além disso, é nítido o sentimento de descontentamento atual frente às exigências impostas pelo consumo desenfreado e pelo frenesi da vida apressada que é partilhada tanto pela poeta quanto pelos indivíduos nas diversas paisagens artificiais urbanas. Sufocados e sem espaço para expressarem suas individualidades, a poeta e os sujeitos comuns - muitos dos quais se encontram em situações degradáveis vivem submersos a um "sistema autocrático de identificação e de resolução de erros", tal como é referido no poema "Vivemos submersos num plasma nutritivo":

\section{Vivemos submersos num plasma nutritivo} que nos garante um crescimento rápido e de excepção 
com talentos singulares, e sonhos que não precisam de ser actualizados basta apenas afinar sua desordem estética.

Temos acesso a uma vida desprovida de acasos, onde colónias de bactérias sangram invejosas, esmagadas a milhas pela radiação do nosso olhar.

Dotados de um sistema automático de identificação e resolução de erros, dirigimos à distância um código sentimental simplificado.

Acumulamos dados, analisamos sinais.

Não conseguimos conceber um desastre maior que a falta de bateria no comando.

(ANGHEL, 2017, p. 47)

Observe-se no poema as menções ao "plasma nutritivo". Essa imagem se desdobra em uma alegoria do mundo digital, remetendo às tecnologias da informação e da comunicação que estão a virtualizar as realidades dos indivíduos, massificando-os todos em conjuntos de dados, algoritmos, que se interconectam. Submersos a esse plasma, não há espaço para atualização de sonhos e, tampouco, há espaço para subjetividades dos indivíduos, já que todos dirigem "à distância um código sentimental simplificado". Os substantivos "bateria", "códigos", "colónias de bactérias", "dados", "desastres", "milhas", "radiação", "sinais" evocam uma paisagem distópica na qual não há qualquer perspectiva futura de vida que valorize as particularidades do sujeito. Tais imagens emblemáticas, tais como a "flor de plástico" em cima da montra de um talho e a "piscina dos pequenos" que intitulam os livros, são representativas desse mal-estar do sujeito no mundo contemporâneo. ${ }^{3}$ Por meio dessas imagens, nota-se que o discurso poético de Golgona Anghel se vale de referências comuns, prosaicas, facilmente identificáveis, o que desvia essa poesia da ideia de alto lirismo, levando a poeta ao encontro dos outros, pessoas comuns nas ruas da cidade. Não à toa, na grande maioria dos poemas, o sujeito lírico se manifesta sempre na primeira pessoa do plural, no tempo presente do modo indicativo, em lugares públicos e de encontro:

\footnotetext{
${ }_{3}^{3}$ Vale a pena lembrar, também, do livro de Golgona Anghel, Vim porque me pagaram (2011), cujos poemas também articulam propostas de partilha de sentimentos desajustados da poeta e os sujeitos citadinos com as massificações do sujeito impostas pelo capitalismo e pelos meios de vida contemporâneos.
} 


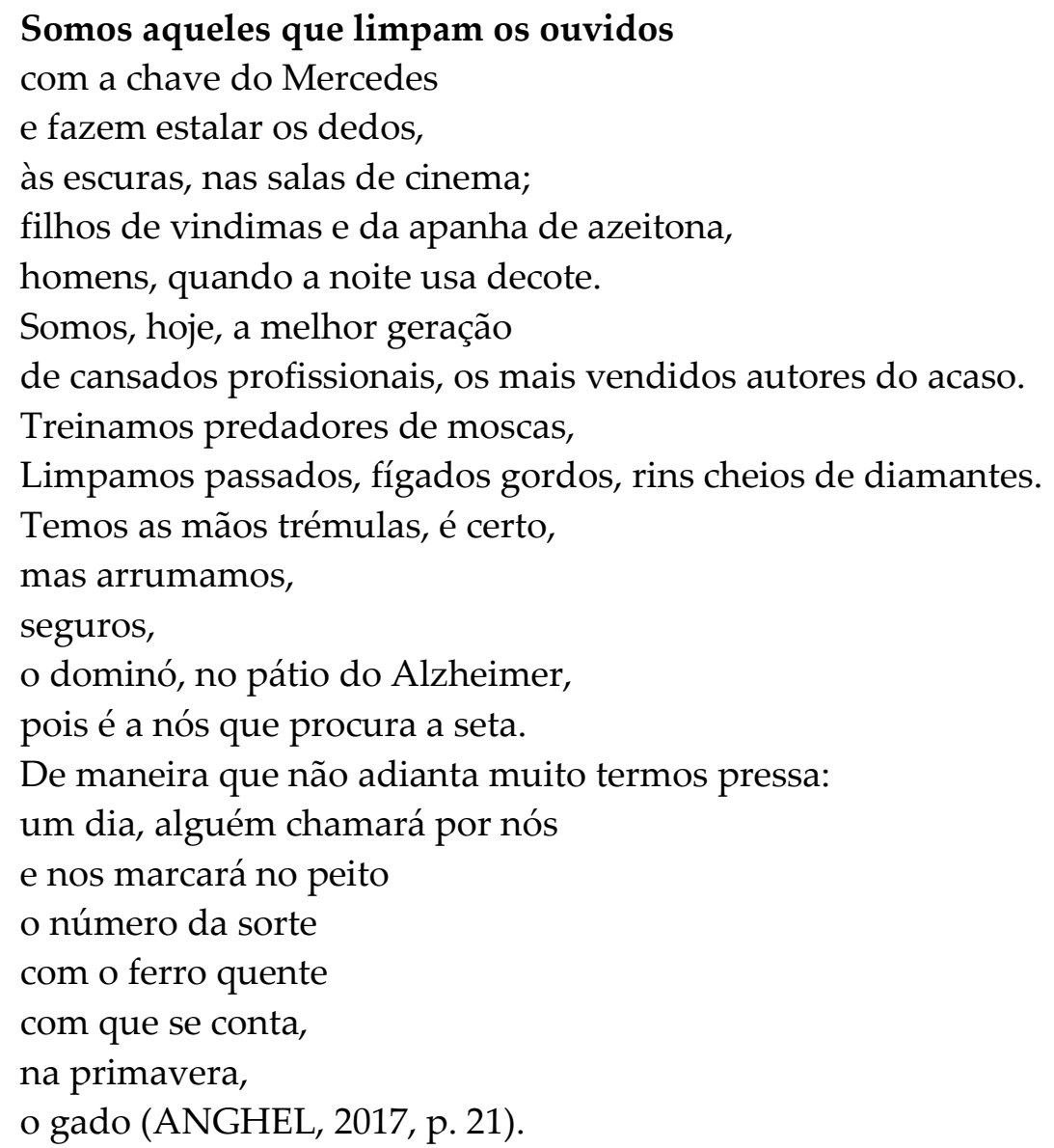

Ao lado dos "filhos de vindimas e da apanha de azeitona", a poeta ironiza e ridiculariza a superficialidade da vida apressada dos sujeitos anônimos que transitam pelas paisagens lisboetas. Juntos, todos formam "a melhor geração de cansados profissionais", que estão a sofrer com as mãos trémulas pelo Alzheimer e por outras enfermidades do mundo pósmoderno. Imersa nesse mundo, a poeta sente-se impotente e mesmo seus livros de poesia tornam-se mercadoria do acaso. Os sentimentos de não pertencimento, de incorporar "as fantasmagorias sinistras do tempo que lhe coube viver" revelam um modo de a poeta, ou melhor, de o sujeito "estar na escrita" por meio de uma abertura ao outro, partilhando os mesmos problemas existenciais e sociais do tempo presente, como se verifica no poema "Escreve sobre os coitadinhos, os feios":

Escreve sobre os coitadinhos, os feios,

Os mal-amanhados.

Não retretes das tardes de Júlia, por detrás dos anúncios de depilação e dos antenados, estão eles. 
A servirem de decoração em salas de espera.

Uns de toga, outros de farda.

A viverem de biscates,

de dinheiro emprestado,

de roupa usada.

Acordam de joelhos.

Andam na pocilga.

Morrerão afogados na merda

mas serão recordados

no mármore (ANGHEL, 2017, p. 27).

Nas três partes que compõem a obra Nadar na piscina dos pequenos, intituladas como "Um rebanho de boas intenções", "Há passos falsos nos mais caros sapatos" e "A minhoca está cansada de torcer no anzol", constata-se o tom irônico e, ao mesmo tempo descrente, da poeta que se vê sem lugar frente às novas ordens econômicas e mentais da sociedade contemporânea. Ao utilizar uma linguagem facilmente assimilada, que se vale de imagens e de alegorias do cotidiano citadino, os poemas possibilitam que os leitores também partilhem dessas mesmas angústias presentes na distopia contemporânea:

Agora que mais nada importa, consolamos as tardes de Domingo com as bifanas das tasquinhas montadas antes do jogo, alguns boatos frescos, discussões sobre Sartre,

o pós-estruturalismo e essa piada que qualquer marxista parolo parece esperto ao pé de um anarquista. $\mathrm{O}$ único interesse que ainda temos em comum é dividir o aluguer e uma garrafa de tinto.

Às vezes, ainda recebemos algum convite, e olha, não é fácil, com o miúdo e tal.

Mas acabamos por ficar em casa.

O desinteresse acumula-se à minha volta como as camadas seculares no tronco de uma sequóia. Fico imune a queixinhas. Lavo sozinho a minha roupa. A minha língua está a ganhar uma espessura lenhosa.

No lugar do grito, um greta. 
Mãos nos bolsos,

bico calado.

Evito vitrinas e espelhos.

Tenho medo que a verdade

me possa desfigurar o rosto (ANGHEL, 2013, p. 53-54).

Por meio de cenas cotidianas que entrelaçam o mais banal, a cultura de massa, ao erudito e literário, "boatos frescos, discussões sobre Sartre", Golgona Anghel se vale de estratégias discursivas transgressivas as quais refletem as querelas do cotidiano de Lisboa a partir do que Guerreiro entende como uma "etologia da vida literária", ou seja, uma poesia que trata mais detidamente dos aspectos humanos como fatos sociais. Logo, as cenas urbanas em suas obras dialogam com a noção de um lirismo figurativo que, tanto Guerreiro quanto Rosa Maria Martelo (2003; 2010), reconhecem como fundamentais na poesia de JMM, cuja voz também ecoa na poesia de Golgona Anghel, como na de outros poetas que começaram a publicar nos anos $1990 \mathrm{e}$ anos seguintes. Em JMM, há a recusa do "lirismo abstrato", ou seja, de um certo conceitualismo que faria parte, por exemplo, de poéticas como de Fiama Hasse Paes Brandão e de Gastão Cruz. Golgona Anghel e Manuel de Freitas - outro poeta contemporâneo, com temática afim - retomam de JMM essa escrita que Martelo chamou de "expressão dominantemente alegórica", ou seja, "apostada em encontrar uma resposta ao mesmo tempo ética e estética para a condição actual da poesia" (MARTELO, 2010, p. 312). Trata-se de uma poética "sem qualidades" e, lembra-nos Martelo, que a designação "sem qualidades" nesses novos poetas se refere à recusa da metáfora. No poema “Faróis, vitrinas e vadias" lemos:

\section{Faróis, vitrinas e vadias,}

ruídos alastrados:

o escuro não sabe outra marcha.

A última das chamas

assalta sombras, atiça vultos,

assusta tantos rostos.

Perto dos espelhos,

os signos tocam missas.

É altura de encurtar a trela - penso -

e de sair batendo com a porta,

mas não antes de tirar uma nota de cinco euros no bolso e de apanhar este cocó do chão.

Anda, Pirusca, que está a ficar tarde e, olha, há gente a ver. 
Anda, levanta a pata, diz boa noite às pessoas.

(ANGHEL, 2017, p. 66)

Nesse e nos outros poemas de Nadar na piscina dos pequenos e, também, em Como uma flor de plástico na montra de um talho, a recusa da metáfora é nítida pela escolha intencional de certa narratividade sobre a vida comum, diária, compondo-se cenas que denunciam os problemas do sujeito mal situados nos ambientes citadinos. No caso de Golgona Anghel, especialmente, trata-se de uma voz extremamente crítica cujo foco de atenção dirige-se para a relação entre poesia e vida urbana neste tempo distópico. Interessa-lhe pensar isso por meio de uma linguagem crítica, desencantada, insatisfeita, que sabe que "só o ouro importa" e a sociedade é surda à poesia. Em sua escrita, cria-se o espaço da comunicabilidade com o outro por meio do reconhecimento de uma linguagem literal, prosaica, simples, que se direciona ao leitor e o leva reconhecer-se no poema:

\section{Não gosto de contar os desastres em detalhe}

mas, se quiserem, posso escrever uma lista com nomes e camas.

Sou bem capaz de molhar o pezinho na história da barbárie, condecorar o medo, cortar-me a mão com que limpo as feridas de uma civilização em queda.

Posso perfeitamente ir afiando o gume da esperança com a flor branca de um cancro.

Sou, em definitivo, este comediante de rua que serve a desconhecidos, em copos pequenos, a medida certa da sua agonia.

Descobre sonhos onde outros só encontram coelhos.

Hoje, por exemplo, quando tirou as luvas, Viu que lhe faltavam dedos (ANGHEL, 2013, p. 18).

A função comunicativa inerente a essa poesia está articulada à noção de partilha que Jacques Rancière (2009, p. 7) discute em seu estudo $A$ partilha do sensível: "partilhar um modo como se determina no sensível a 
relação entre um conjunto partilhado e a divisão de partes exclusivas". Logo, as cenas da escrita de Golgona Anghel revelam uma poeta de partilha do sensível. Seus gestos de escrita são realizados a partir de lugares de encontro marcados pelos afetos que unem os sujeitos nos espaços desterritorializados da sociedade pós-moderna. Em um poema específico de Nadar na piscina dos pequenos, a poeta faz uma referência intertextual explícita a JMM:

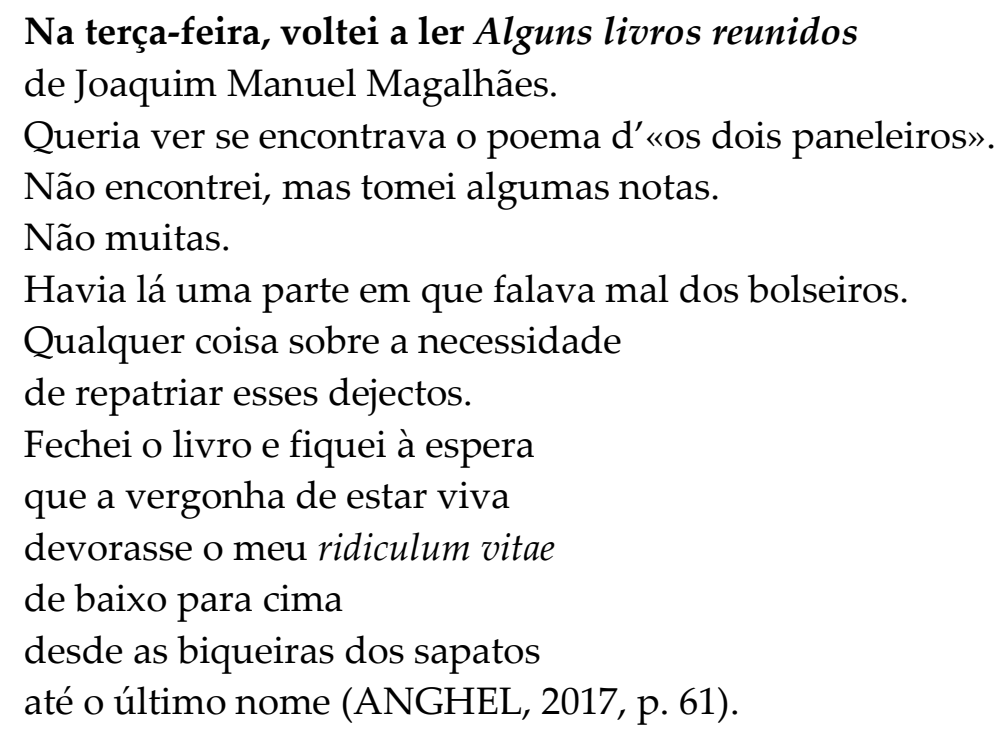

A percepção de descontentamento, do mal-estar e das constantes perdas de valores em função do capitalismo tardio ${ }^{4}$ se materializam em sua poesia em diferentes circunstâncias e cenários da Lisboa contemporânea. Nessa cidade, nota-se que as paisagens, ou melhor, as "despaisagens" servem como pretextos para se pensar o fracasso e a anulação diária dos sujeitos. Extremamente distópica, as ruínas da paisagem urbana aparecem em sua escrita para indicarem a insatisfação da poeta - que está atenta às vivências das pessoas comuns - com a deterioração de valores em uma sociedade consumista e indiferente ao mundo solidário. A esse respeito, leia-se o poema "Muito poderia dizer-se, é certo":

Muito poderia dizer-se, é certo, da sempre excessiva distância que separa a galinha do seu voo: sinto-me, nos dias de colheita, como um rapsodo estéril

\footnotetext{
${ }^{4}$ Referimo-nos aos estudos Pós-modernismo: a lógica cultural do capitalismo tardio (2007), de Fredric Jameson, e As ilusões do pós-modernismo (1998), de Terry Eagleton.
} 
que, de repente, vomita um ovo.

Mas talvez seja em vão fazê-lo agora,

quando da rima ficam apenas escombros.

Onde havia medo, disciplina e poder,

temos descanso, "cultura" e diversão.

Os tropos caem como figos secos no esterno oco dum soneto:

aqui apenas as hienas e o vento aparecem ainda para afiar a língua.

Somos o eco leigo de um trambolhão a imitar um ditirambo.

Já derreteram flautas e sonhos para alimentar a lavra de canhões.

Os sátiros foram buscar febras e tabaco.

Dizem que a Lolita cumpriu, há pouco, trinta anos.

O paraíso, já sabemos, tem as suas contas em dia.

Alguém devia, no entanto,

especializar-se em originais e outras classes de infernos.

Este miúdo, talvez, que nos ensina,

calado e confiante,

com a ponta da tíbia de frango,

na gordura que sobrou no prato,

o contorno de uma chucha (ANGHEL, 2013, p. 16-17).

Nesse poema, destacam-se descrições dos espaços triviais e coletivos de Lisboa, tais como as "montras", os "talhos"5 e as "piscinas" públicas. Nesses espaços coletivos transitam os diversos sujeitos circunscritos no tempo atual. Nos espaços de encontro urbano, compartilha-se um morrer em conjunto por meio da dicção satírica e, por vezes, cômica, quando a poeta destaca as belezas artificias, efêmeras e superficiais da modernidade líquida, uma vez que "derreteram flautas e sonhos para alimentar a lavra de canhões". Ressalte-se a escolha lexical nesse poema: "rapsodo estéril", "eco leigo", "tíbia de frango", "contorno de uma chucha" cujas referências, embora deslocadas e postas em movimento, denotam uma lucidez sobre a realidade perecível, frágil. Essas figuras postas em movimento marcam a negatividade da poesia sem espaço nessa realidade em que não há crenças no futuro. Mescla-se à distopia do presente a narrativização no poema de situações comezinhas do dia a dia, que flagram sujeitos nulos nos espaços artificiais da cidade. Ainda nesse poema, focaliza-se um miúdo - uma criança - que compartilha consigo situações de extrema pobreza em uma cidade onde sujeitos invisíveis passam anônimos entre anônimos. Ao mesmo tempo, notase um humor melancólico em um jogo de apropriação de referências

\footnotetext{
5 “Açougues", em português brasileiro.
} 
intertextuais que funcionam, segundo Laurent Jenny (1979), como uma "máquina perturbadora", que desestabiliza os sentidos estratificados. O olhar crítico, inerente à prática intertextual, possibilita pequenas intervenções que operam nos sentidos e ganham outras funções por meio de partilhas. Os poemas "Dantes fazia grandes escândalos" e "Canta-nos algo, Capitú" se ocupam dessas pequenas intervenções de partilhas:

\section{Dantes fazia grandes escândalos,}

ia embora,

abria com uma revolução a primeira página do Expresso.

Estava, é certo, habituada a grandes poemas:

Os Lusíadas, a Divina Comédia.

Mas o destino decidiu por nós.

Meteu o Barthes

debaixo dos pneus de um furgoneta de lavanderia;

contaminou o Foucault com HIV;

encerrou o Althusser num manicómio.

Deus, é claro, não era estruturalista.

Podia escrever-te um haiku

para simplificar a coisa.

Lembro-me de Santo Agostinho, por exemplo,

desse verão de 384 ,

duma mulher no quarto,

com um livro,

a ler

sem conseguir articular

nenhuma palavra (ANGHEL, 2013, p. 57).

\section{Canta-nos algo, Capitú}

uma música de fracassos, alimentada por balas perdidas e chamadas distantes.

Canta-nos algo,

mexe a anca, estremece as mamas,

cospe esse talento pela noite dentro.

Não te acanhes, nós já vimos tudo.

Basta-nos a faísca de um copo para incendiar um iceberg.

A árvore da nossa vida é este ramo de coentros

que borrifamos nos canteiros,

como se fossem rosas.

Canta-nos algo, Capitú!

Uma música de fundo, sem letras, sem palco e sem violinos. 
Sê meu ruído lento, o meu tom de vício.

Apesar da calvície,

sou ainda este gato gigante

que dormia nas montras

e se deixa acariciar por toda a gente.

Vem cá tocar o bicho.

Vais ver, Capitú,

qualquer vómito tem um mito lá dentro (ANGHEL, 2017, p. 22).

Ao deslocar e cruzar diversas referências intertextuais, tais como nomes de obras literárias canônicas, nomes de personagens, dados biográficos sobre filósofos e pensadores estruturalistas e pósestruturalistas, Golgona Anghel ressalta a urgência de que todos reflitam sobre as emergências do momento atual e que a poesia volte a falar dos sentimentos. Não à toa, ao dar voz a mais famosa personagem de Machado de Assis, a enigmática Capitu, - que no poema de Golgona Anghel aparece com acento diferencial na letra " $u$ " - possibilita-se que essa nova criação intertextual proposta pela poeta possa, também, partilhar dos mesmos inconformismos comuns a todos, uma vez que Althusser, Barthes e Foucault foram silenciados porque "Deus, é claro, não era estruturalista".

Observa-se, ainda, que os poemas transcritos partem da perspectiva do "voltar a falar de si", ou seja, parafraseando JMM, de voltar aos sentimentos que podem ser compartilhados uns com os outros, bem como à ordem das mágoas partilhadas por meio de uma linguagem literal. Sua poética é, a nosso ver, fortemente marcada por certa perspectiva lírica de JMM e de outros poetas da chamada Geração Cartucho, ${ }^{6}$ nos quais desenvolve-se uma preocupação ética que está entremeada à presença corpórea dos poetas [sujeitos] e à volta dos afetos. Logo, essa po-ética ${ }^{7}$ de Golgona Anghel, semelhante a outros poetas de agora, constrói-se a partir do retorno ao real por meio desse "[...] desencanto que deixou de cantar, [de] vê-lo na figura do espelho, na perspectiva de quase de ninguém, de

\footnotetext{
${ }^{6}$ Ver o ensaio "Cartucho e as linhas de renovação da poesia portuguesa na segunda metade do século XX", de Rosa Maria Martelo (2010), no qual a estudiosa aponta para o programa poético de JMM que já se encontrava nos cinco poemas pertencentes ao cartucho, ou melhor, a "aquilo" como Fiama Hasse Pais Brandão se referia à proposta inusitada de livro de poemas.

${ }^{7}$ Ao se referir às recentes poéticas contemporâneas portuguesas que se voltam para ao afeto, à consciência e à percepção da realidade pelo sensível, Ida Alves, em algumas de suas palestras, definiu como "po-éticas" as cenas de escrita da recente poesia cujos poetas criam um outro modo de escrita por meio da entrega dos sentimentos e no encontro com o outro. A esse respeito, ver a palestra "A política da poesia, por uma poética". Disponível em: https://www.youtube.com/watch?v=yEPZxdme2U0
} 
um corpo pronto a dizer até as manchas a exacta superfície por onde vai, onde se perde" (GUERREIRO, 2003, p. 67).

Essa linha de força surgida com JMM - cuja escrita poética está fortemente ligada à cidade e à vida contemporânea marcada pela distopia ao reconhecer que o projeto moderno não mais perdura - é, como temos constatado, bastante visível na poética de Golgona Anghel que, por sua vez, prima em criar um lirismo ético que execra o consumismo e a superficialidade das imposições capitalistas. No poema transcrito abaixo, observa-se tais evidências:

\author{
Encontrámos as partes, \\ mas ainda não o conjunto. \\ Falta-nos esta última força. \\ Falta-nos a esperança \\ como uma espuma branca que nos projeta e nos una. \\ Procuramos esse sustento salutar: \\ conviver, \\ perseguidos por uma espécie de incontinência verbal. \\ Na juventude, começávamos com uma boneca de corda, \\ a que demos tudo o que tínhamos. \\ O fracasso estava, no entanto, treinado \\ para receber-nos, com luvas gigantes, \\ como se fôssemos bolas de basebol. \\ Continuamos calados. À procura. Com fome. \\ Não podemos fazer mais (ANGHEL, 2017, p. 23).
}

Em suma, nos poemas de Como uma flor de plástico na montra de um talho e de Nadar na piscina dos pequenos a escolha por uma dicção risível funciona como uma atitude transgressiva à ordem vigente. Neles, Golgona Anghel reconhece, por meio da crítica às forças mercadológicas e da ironia contra o cenário das exigências da sociedade pós-moderna, a pouca relevância do seu lugar de fala, já que a poesia parece não ter sentido. Ao partilhar do descontentamento da poesia de JMM - que a levou a reler alguns versos e a anotar algumas formas de encontros com o outro, tal como presente no verso do poema "Na terça-feira, voltei a ler Alguns livros reunidos" em que ela o cita - nota-se que Golgona Anghel cria sua própria dicção pessimista na recente poesia portuguesa das primeiras décadas do século XXI. 


\section{REFERENCIAS}

ALVES, Ida. A política da poesia, por uma po-ética. Disponível em: https://www.youtube.com/watch?v=yEPZxdme2U0. Acesso: 12 fev. 2021.

ANGHEL, Golgona. A metafísica do medo: leituras da obra de Al Berto. Tese (Doutorado em Estudos Portugueses) - Faculdade de Letras, Universidade de Lisboa. Lisboa. 2008.

ANGHEL, Golgona. Como uma flor de plástico na montra de um talho. Porto: Assírio \& Alvim, 2013.

ANGHEL, Golgona. Nadar na piscina dos pequenos. Porto: Assírio \& Alvim, 2017.

ANGHEL, Golgona. Sacrifiquei sem nenhum remorso. ELyra: Revista da Rede Internacional Lyracompoetics, n. 5, p. 125, 2015.

ANGHEL, Golgona. Vim porque me pagavam. Lisboa: Mariposa Azual, 2011.

BERGSON, Henri. O riso: ensaio sobre o significado do cômico. Trad. Maria Adriana Camargo Cappello. São Paulo: Edipro, 2018.

ECO, Umberto. O cômico e a regra. In: Viagem na irrealidade cotidiana. Rio de Janeiro: Nova Fronteira, 1984, p. 343-353.

EAGLETON, Terry. As ilusões do pós-modernismo. Trad. Elizabeth Barbosa. Rio de Janeiro: Jorge Zahar Editor, 1998.

GUERREIRO, António. Um pouco de vida, um pouco de poesia. Telhados de vidro, n. 1, p. 65-74, 2003.

JAMESON, Fredric. Pós-modernismo: a lógica cultural do capitalismo tardio. Trad. Maria Elisa Cevasco. São Paulo: Ática, 2007.

JENNY, Laurent. A estratégia da forma. Poétique, n. 27, p. 5-49, 1979.

MARTELO, Rosa Maria. Alegoria e autenticidade. In: MARTELO, Rosa Maria. A forma informe: leituras de poesia. Porto: Assírio \& Alvim, 2010, p. 303-319.

MARTELO, Rosa Maria. Cartucho e as linhas de renovação da poesia portuguesa na segunda metade do século XX. In: MARTELO, Rosa Maria. A forma informe: leituras de poesia. Porto: Assírio \& Alvim, 2010, p. 155-178. 
MARTELO, Rosa Maria. Cenas de escrita (alguns exemplos). In: MARTELO, Rosa Maria. A forma informe: leituras de poesia. Porto: Assírio \& Alvim, 2010, p. 323-343.

RANCIÈRE, Jacques. A partilha do sensível: estética e política. Trad. Mônica Costa Netto. São Paulo: Editora 34, 2009.

Recebido em 15 de maio de 2021

Aprovado em 8 de setembro de 2021

Paulo Alberto da Silva Sales

Docente da área de Linguagens no Instituto Federal Goiano, Câmpus Hidrolândia, e no Programa de Pós-Graduação Stricto Sensu em Língua, Literatura e Interculturalidade da Universidade Estadual de Goiás, Campus Cora Coralina. Desenvolve Estágio Pós-Doutoral em Estudos de Literatura na Universidade Federal Fluminense, sob supervisão da Profa. Dra. Ida Alves e cosupervisão da Profa. Celia Pedrosa.

Contato: paulo.alberto@ifgoiano.edu.br

(DD: http://orcid.org/0000-0001-9980-2561

\begin{abstract}
A Revista Desassossego utiliza a Licença Creative Commons Attribution que permite o compartilhamento do trabalho com reconhecimento da autoria e publicação inicial neste veículo - Attribution-NonCommercial-NoDerivates 4.0 International (CC BY-NC-ND 4.0), e reconhece que os Autores têm autorização prévia para assumirem contratos adicionais separadamente para distribuição não-exclusiva de versão dos seus trabalhos publicados, desde que fique explicitado o reconhecimento de sua autoria e a publicação inicial nesta revista.
\end{abstract}

